\title{
What Do Grandmothers Think about Self-esteem? American and Taiwanese Folk Theories Revisited
}

Grace E. Cho, Middlebury College, Todd L. Sandel, University of Oklahoma, Peggy J. Miller, University of Illinois at Urbana-Champaign, and Su-hua Wang, University of California at Santa Cruz

\begin{abstract}
The study investigates European American and Taiwanese grandmothers' folk theories of childrearing and self-esteem, building on an earlier comparison of mothers from the same families. Adopting methods that privilege local meanings, we bring grandmothers' voices into the conversation about childrearing, thereby contributing to a deeper understanding of intergenerational nuances in folk theories. In each cultural case, 16 grandmothers of 3-year-olds participated in in-depth interviews that were customized according to local communicative norms. Although self-esteem emerged as a central organizing concept in the folk theories of European American mothers, grandmothers spoke in two voices, either echoing their daughters or invoking a counter-discourse of wariness towards self-esteem. By contrast, Taiwanese mothers and grandmothers resembled one another-but differed from their American counterparts-in treating self-esteem as peripheral in childrearing. Results contribute to the growing consensus that self-esteem is a culture-specific childrearing goal and suggest that the European American tendency to valorize self-esteem varies by generation.
\end{abstract}

Keywords: folk theories; culture; grandmothers; self-esteem

There is growing recognition of the need to create a culture-sensitive understanding of parenting, one that takes into account caregivers' 'folk theories' or 'ethnotheories' (Bruner, 1990, 1996; Gaskins, Miller \& Corsaro, 1992; Harkness \& Super, 1992, 1996). Parental folk theories are culturally organized, collectively shared ideas regarding the nature of children and childrearing (Harkness \& Super, 1996). These informal systems of beliefs, attitudes, and values are related to other local meaning systems, on the one hand, and to parenting practices, on the other, and they shape and are shaped by the experiences of everyday life.

Although developmentalists assume that parents' folk theories are socially and historically situated, most research has dealt with variation across cultures, with little 
attention to within-culture variation. In this respect, studies of parents' folk theories reflect a more general trend in the study of parents and children, namely that cultural meanings often are described at highly global levels, with cultural knowledge portrayed as consistent, timeless, and characteristic of entire populations. Several cultural psychologists have underscored the need for more research that takes into account within-culture diversity (Bock, 1994; Cervantes, 2002; Miller, 1994).

Especially neglected is variation across generations. Although generational differences are recognized as critically important in the study of immigrant groups (Garcia Coll \& Pachter, 2002; Suarez-Orozco \& Suarez-Orozco, 2001), parents and grandparents who remain in the same society or even the same community are not immune to social change. In fact, recent historical analyses reveal dramatic changes in American childrearing fashions and expert advice to parents (e.g., Grant, 1998; Hulbert, 2003). In light of these considerations, this article offers a rare intergenerational perspective on beliefs about childrearing. We investigate European American and Taiwanese grandmothers' folk theories of self-esteem, building on an earlier comparison of mothers from the same families. Our intention is to contribute to a deeper understanding of within-culture nuances in folk theories from the two cultures.

Our decision to focus on childrearing and self-esteem (or alternative ideas) arises from the recognition that parental folk theories of self-development have been studied relatively little. This is surprising in light of mounting evidence that construals of the self are culturally variable and that North Americans consistently score higher on measures of self-esteem than their Asian counterparts (Greenfield \& Cocking, 1994; Heine \& Lehman, 2003; Heine, Lehman, Markus \& Kitayama, 1999; Markus \& Kitayama, 1991; Triandis, 1990). The cultural plurality of selves raises a fundamental developmental question: What are the processes by which different construals of self are created (Miller, Fung \& Mintz, 1996; Wiley, Rose, Burger \& Miller, 1998)? How can we explain, for example, how children living in certain cultural communities (e.g., middle-class, European American) come to define themselves in terms of their individual choices and preferences or why they grow up to have a need for positive self-regard? We assume that a better understanding of parental folk theories of self-development - and the practices that they inform, motivate, and rationalize - will help to answer these questions.

In the remainder of this introduction, we review research on variation within and across cultures in parental folk theories as well as research on grandparents. To set the stage for the present study of grandmothers, we then briefly recap findings from our recent study of European American and Taiwanese mothers (Miller, Wang, Sandel \& Cho, 2002).

\section{Cultural Variation in Beliefs about Childrearing and Self-esteem}

There is increasing evidence that promoting children's self-esteem is a culturespecific childrearing goal. Several studies indicate that European American parents place greater value on children's self-esteem, compared with their counterparts from Japan and China (Stevenson \& Stigler, 1992; Stevenson, Lee, Chen, Stigler, Hsu \& Kitamura, 1990) and from Puerto Rico (Harwood, Miller \& Irizarry, 1995; Harwood, Schoelmerich, Schulze \& Gonzalez, 1999). A recent special issue of Parenting: Science and Practice devoted to the topic of cultural ethnotheories added further weight to this conclusion: when compared with Greek, Puerto Rican, or Taiwanese mothers, European American mothers were more likely to endorse self-esteem or self- 
maximization as socialization goals (Miller \& Harwood, 2002; Miller et al., 2002; Tamis-LeMonda, Wang, Koutsouvanou \& Albright, 2002).

Research pertaining to within-culture variation in folk theories of self-esteem is sparse. Harwood et al. (1995) found that both middle-class and working-class European American mothers valued 'self-maximization', but working-class mothers endorsed this goal less frequently and worried that its attainment would be problematic in light of economic hardship and limited opportunities. Similarly, Bracey, Cho, and Miller (2003) found that African American parents expressed beliefs similar to their European American counterparts but voiced distinct concerns regarding challenging life circumstances, including racial prejudice and discrimination, that could adversely affect their children's self-esteem. Other recent studies point to subtle but important class-based differences in parenting beliefs and practices related to selfdevelopment (Cho \& Miller, 2004; Okagaki \& Divecha, 1993; Wiley et al., 1998). Taken together, these studies support Markus and Kitayama's (1994) argument that marginalized groups within the United States - women, minorities, the poor, and the unschooled - are less likely to internalize the dominant cultural frames for defining selfhood.

\section{Grandparents Voices are Missing}

The overwhelming reliance on mothers as the sole representatives of parenting beliefs is a serious concern. Other important caregiving figures, such as grandparents, have been understudied. Extended family members not only serve as major caregiving figures for many children, particularly African American, Latino, and Asian (Gadsden, 1999; Parke \& Buriel, 1997), they are also important sources of parental ideas (Okagaki \& Divecha, 1993). In the most recent Handbook of Parenting, Smith and Drew (2002) point out that examining viewpoints from multiple generations is surprisingly neglected. Cross-cultural research on grandparenthood and grandparents' ideas regarding childrearing are even sparser, with almost all of the evidence coming from modern urban, industrial societies, particularly the United States. The current study attempts to remedy this omission by including the voices of Taiwanese grandmothers.

With substantial increases in life expectancy, many children grow up knowing both sets of grandparents, especially grandmothers. In the United States, despite great variability in the frequency of contact between grandparents and grandchildren, the modal trend is for the relationship to be perceived as positive and important by both generations (Smith \& Drew, 2002). Even in cases where visitation is infrequent, parents and children often call grandparents on a regular basis and turn to them as sources of support and affection.

In many Asian cultures, grandparents play a very substantial role in children's lives. Family roles are structured by gender (Ho, 1987; Sun \& Roopnarine, 1996; Wolf, 1978, 1992) and age (Wolf, 1972/1987), and deference is given to elders (Liu \& Chien, 1998; Sandel, 2002, 2003; Strom, Strom \& Shen, 1996). Grandparents are expected to be highly involved in childrearing, responsible for decision-making, and caring for children throughout their lives (Wolf, 1978, 1972/1987). Parents provide advice and guidance even after the child becomes an adult and moves out of the household, developing a lifelong bond of 'mutual dependence' (Hsu, 1981/1991; Stafford, 1995). These findings highlight the importance of considering grandparents' folk theories of childrearing because they are likely to be both direct (e.g., face-to-face interaction 
with grandchildren) and indirect (e.g., supporting and advice-giving to parents) socializing agents.

\section{European American and Taiwanese Mothers Folk Theories}

The current study of grandmothers builds directly on an earlier study of mothers from the same families (Miller et al., 2002). We found that self-esteem was a central organizing concept in the folk theories of European American mothers of 3-year-olds, but not in the folk theories of their Taiwanese counterparts. The European American mothers introduced the term self-esteem before the researcher asked about it, invoked self-esteem repeatedly when discussing other childrearing issues, and gave elaborate responses. These mothers believed that self-esteem provides a foundation for psychological strengths. Children who have high self-esteem are able to grow psychologically, form healthy relationships, compete in the world, but most importantly, they are happy, persist in the face of failure, and are willing to try new things. They also believed that parents play a key role in cultivating children's self-esteem by praising and encouraging children's efforts and by providing opportunities for mastery and accomplishment.

In contrast, Taiwanese mothers had little to say about 'self-respect-heart/mind' (a Taiwanese term approximating 'self-esteem'). Only a few of the Taiwanese mothers brought up the terms prior to specific questions from the interviewer, and no one invoked these terms repeatedly. When asked directly about self-respect-heart/mind, many of the Taiwanese mothers did not find the topic to be very meaningful. The few mothers who did talk regarding self-respect-heart/mind believed that high self-respectheart/mind creates psychological vulnerabilities - frustration, stubbornness, and unwillingness to listen-whereas American mothers believed that high self-esteem creates psychological strengths.

In sum, Miller et al. (2002) found qualitative differences in Taiwanese and European American mothers' folk theories of childrearing. Self-esteem loomed large in American mothers' folk theories but not in Taiwanese mothers. The latter were much more concerned about moral education, growing up naturally, and 'watching' children. Although these results indicate that the meanings associated with self-esteem are culture-specific, it is likely that they are also generation-specific. Mintz (1999) found that European American mothers contrasted their approach to childrearing with their parents' approach, citing self-esteem as a point of difference. Taiwanese ideas regarding childrearing are changing as well, due in part to rapid political and social change (Sandel, 2000).

Thus, in the current study we revisit the two questions posed by Miller et al. (2002), but shift our focus to grandmothers: what are the meanings that European American and Taiwanese grandmothers associate with the idea of self-esteem? And what are the local folk theories that contextualize this idea or that offer alternative formulations of the goals and values of childrearing? We approach these questions comparatively: How do European American and Taiwanese grandmothers compare to each other? And how do grandmothers compare with mothers from the same families? In addition to these substantive goals, our methodological goal is to understand grandmothers' meanings in their own terms. Mindful of the fact that grandmothers are so underrepresented in research, we chose in-depth interviewing as the best way to begin to make sense of their childrearing beliefs. And because we want to understand grandmothers from two different cultures, we took an ethnographic approach, customizing our procedures 
according to local ways. This study thus furthers our long-standing methodological project of devising ways to make culturally valid comparisons within and across sociocultural groups (Miller, Wiley, Fung \& Liang, 1997; Miller, Hengst \& Wang, 2003).

\section{Method}

The study was situated in two large towns in rural areas: Centerville (pseudonym), located in the Midwestern United States and Chhan-chng (pseudonym), located in central Taiwan. These communities are described in detail in Miller et al. (2002). Before providing more information regarding the participants and procedures, we outline our methodological approach.

\section{Ethnographic Approach}

Researchers who seek to understand child development in cultural context are increasingly aware of the pitfalls of exporting to other cultures questions and procedures developed in the U.S. and increasingly aware of the value of ethnographic research for remedying this problem (e.g., Goncu, 1999; Greenfield \& Suzuki, 1998; Jessor, Colby \& Shweder, 1996; Shweder, Goodnow, Hatano, LeVine, Markus \& Miller, 1998). Although it is impossible to do justice here to the vast literature on ethnography, we briefly outline some key features. The goal of ethnographic research is to understand meanings from the standpoint of the people being studied, with the understanding that culturally organized meaning systems are more or less collectively shared (see e.g., Corsaro \& Miller, 1992; Erickson, 1986; Miller et al., 2003; Woolcott, 1995). In pursuing this goal, ethnographers use a combination of interviewing and participantobservation in the local scene. They try not to mistake their own deeply taken-forgranted, culturally saturated understandings for those of the study participants. If the goal is to appreciate the folk theories of Taiwanese parents and the ethnographer is American, the process of bringing the parents' (Taiwanese) folk theories into focus will expose the ethnographer's own (American) folk theories. Thus, even when ethnographers study a single cultural case, their enterprise is implicitly comparative. In an increasingly globalized world, in which it is impossible to draw neat boundaries around cultures, individuals have first hand experience of multiple cultures. Our research team included individuals with varying life experiences in the two cultures: Wang grew up in Taiwan and the others grew up in the United States; Sandel lived in Taiwan for eight years and has a Taiwanese wife. The team's bicultural expertise was an important resource, allowing us to draw on multiple insider/outsider perspectives in conducting the study and interpreting the findings.

This expertise was especially important in helping us to customize the procedures according to local practices, a guiding principle of ethnographic work (Miller et al., 2003). Miller et al. (2002) illustrated this principle, as applied to interviews with mothers. In Centerville, researcher and participants shared an interview script, allowing them to collaborate in the production of the communicative event of 'interviewing'. However, in Chhan-chng, the interview had to be altered to fit with local communicative norms. A more conversational approach was adopted in which the mothers were granted more control over topics, multiple speakers were accommodated, and the ethnographer joined in with everyday domestic tasks. In other words, different communicative practices had to be honored in the two research sites to allow the talk to unfold in ways that were equivalently meaningful. In the current study, we 
followed the same approach when working with grandmothers, 'interviewing' American grandmothers and 'conversing' with Taiwanese grandmothers.

Similarly, qualitative differences in family organization and relationships between generations required that we focus on paternal grandmothers in Chhan-chng and maternal grandmothers in Centerville and that we recruit grandmothers first in Chhan-chng and mothers first in Centerville. These alterations, described further below, were necessary to create procedures that were culturally appropriate in the two sites.

\section{Participants}

At each research site 16 grandmothers participated in the study. Each had a 3-yearold grandchild. The families in Centerville were middle-class, English-speaking, European American families (see Miller et al., 2002 for more detailed demographic information). The Chhan-chng families were native-born Taiwanese; the grandmothers spoke primarily Tai-gi (also called Taiwanese, Hokkien, and Southern Min), whereas the mothers were bilingual in Tai-gi and Mandarin. The Centerville grandmothers were slightly older (mean $=63$ years) and better educated (all had at least 12 years of education) than the grandmothers in Chhan-chng (mean $=57$ years, mean education level of 6 years). The Centerville mothers were also older (mean $=33$ years) and better educated (most had at least a B.A.) than the mothers in Chhan-chng (mean $=25$ years, mean educational level of 14 years). However, both groups of families were relatively privileged within their respective communities. The average number of children per family was three in Centerville families and two in Chhan-chng.

\section{Household Organization and Caregiving Customs}

Household organization and caregiving arrangements differed. In Centerville, nuclear family households prevailed, with all children co-residing with their parents. Only five had a grandparent who lived nearby, i.e., within an hour's drive. In contrast, 14 out of the 16 Chhan-chng families followed the traditional pattern of living in the same household with the paternal grandparents. The two children who did not co-reside with their grandmothers lived in the same community (one lived next door) and saw their paternal grandmothers on a daily basis.

Consistent with these patterns of co-residence, grandmothers played different roles $v i s-\grave{a}$-vis their grandchildren. Centerville mothers were either the primary caregivers or shared childcare responsibilities with nonfamily members. Even when both parents worked outside the home, the children attended day care or were cared for by babysitters, rather than by grandparents. Chhan-chng grandmothers, on the other hand, played a major caregiving role for 10 of the 16 children, which is consistent with other studies in Taiwan (Strom et al., 1996; Wolf, 1972/1987).

In keeping with these contrasting family structures and caregiving customs, we interviewed maternal grandmothers in Centerville and paternal grandmothers in Chhan-chng. When Centerville mothers were asked if one of the grandmothers would be interested in sharing her views on childrearing, they took for granted that we should interview their own mothers. Even when the paternal grandmother lived in town and the maternal grandmother lived out of state, the mother volunteered her own mother. This is consistent with several studies in Western cultures which reported that maternal grandmothers were more involved with the grandchildren than were paternal grandmothers (Smith, 1995). Chan and Elder (2000) proposed that the matrilineal 
advantage in American grandparent-grandchild ties arises from better relations between mothers and their own mothers.

In parallel fashion, we interviewed paternal grandmothers in Chhan-Chng. This decision was consistent with the predominant family structure of our Taiwanese participants (see Sandel, 2000, 2002, 2003 for further description of family structure and life in Chhan-chng) and with the cultural assumptions of Mr. and Mrs. Dyoo, local residents who helped us recruit participants (described further below). It was obvious to them that the paternal grandmother was the appropriate grandmother to talk with and that the initial approach to the family should be made through her, not through her daughter-in-law.

\section{Procedures}

Recruitment. We recruited Centerville mothers through the participant pool at the university, local Protestant and Catholic churches, schools, and personal contacts. The initial contact was by phone. The researcher invited the mother to participate in an interview study regarding childrearing and explained that we also hoped to later interview her mother or mother-in-law. Most mothers readily agreed to participate. As mentioned earlier, all nominated the maternal grandmother to be interviewed. The grandmothers were contacted by phone, and all agreed to participate. Self-esteem was not mentioned during this initial contact.

In Chhan-chng, participants were recruited primarily by Sandel's mother- and father-in-law. As lifelong residents of this small and close-knit community, Mr. and Mrs. Dyoo were known to virtually everyone. Mr. or Mrs. Dyoo contacted the grandmothers first, then accompanied the researcher to the family's home, introducing the researcher and explaining again the purpose of the visit (to learn about childrearing). Their assistance in recruiting participants and making introductions was critical to our ability to gain participants' trust and engage in conversations which were framed within local cultural practices. Once the Chhan-chng grandmothers were interviewed, mothers were subsequently invited to participate, and all agreed to do so.

Questions for Grandmothers. We used the same set of questions that we had used with the mothers except that grandmothers were asked to think about the questions as they pertained to their 3-year-old grandchildren. In addition, they were sometimes asked to reflect back to when they were raising their own young children. As explained in our earlier report, we chose questions with an eye to balancing Taiwanese and European American perspectives, culling questions from Mintz's (1999) protocol for interviewing European American mothers, and by Fung (1994) for interviewing Taiwanese mothers. Content areas included childrearing goals and values, discipline, strategies for promoting development, sources of childrearing information, shame and pride, and self-esteem and related ideas. The interview protocol was intended to provide a rough guideline for conversation; interviewers were encouraged to follow the grandmother's lead.

However, the researchers waited until late in the interview to ask questions about self-esteem. These included: (1) how do you understand the meaning of the term, 'selfesteem', (2) when you were raising your children, did you try to foster their selfesteem, (3) do you try to foster your grandchild's self-esteem, (4) do you think self-esteem plays an important role in young children's development? Why or why not, (5) how do you think high or positive self-esteem could benefit your grandchild, (6) 
does shaming lower children's self-esteem, and (7) do you think a person's self-esteem could ever be too high? Would this be a problem? If so, how? (The complete set of interview questions is available upon request from the authors.)

A word should be said regarding translation. Because there is no term in Mandarin Chinese or Tai-gi (Taiwanese) that directly translates as 'self-esteem', we used the two terms that most closely approximated the meaning of self-esteem: ' $z i$ zun xin' in Mandarin or 'chu chun sim' in Tai-gi, which literally translates to 'self-respect-heart/mind' and ' $z i$ xin xin' in Mandarin or 'chu sin sim' in Tai-gi, which literally translates to 'self-confidence-heart/mind'. When conducting the research in Chhan-chng, the researchers favored 'self-respect-heart/mind' but sometimes used the related term, 'self confidence-heart/mind', when it better conveyed the meaning of the question as originally framed in English (for a discussion of the difficulties of mapping and translating emotion terms across languages and cultures, see Harkins \& Wierzbicka, 2001; Wierzbicka, 1999).

Conversing with/Interviewing Grandmothers. Half of the American grandmothers were interviewed by phone because they lived out of town or in other states; four were interviewed in their homes, two in the children's home, and two elsewhere. Like their daughters, the American grandmothers found the interview to be a familiar and comfortable speech activity.

This was not the case for the Taiwanese grandmothers. Like their daughters-in-law, they did not share an interview script with the researcher. Thus, in order to fit in with local communicative practices, the researcher abandoned the 'interview' format in favor of informal 'conversation' embedded in everyday domestic activity (see Miller et al., 2002 for further details). All of these conversations occurred in the grandmothers' homes, and roughly half of the Taiwanese participants conversed with the researcher in the presence of the other party. ${ }^{1}$

The conversations/interviews were conducted in the grandmother's native language, English for the American grandmothers and Tai-gi for the Taiwanese grandmothers. They were audio-recorded and lasted for one to two hours. Researchers kept field notes regarding the physical space, participants, circumstances, and other relevant information.

Analysis and Interpretation of Data. The conversations/interviews were transcribed verbatim in English or Tai-gi and coded in the same languages by researchers who were fluent speakers.

We examined the grandmothers' talk in order to identify features of their folk theories of childrearing, especially as these pertained to self-esteem and to key alternative ideas expressed by the Taiwanese mothers (growing up naturally, moral education, 'watching' children). Following standard practice for deriving emic categories, our analysis of the patterns in the participants' talk emerged through repeated passes through the data (Bloom, 1978; Gaskins et al., 1992, Miller et al., 2003). We reviewed and re-reviewed the tapes and transcripts in order to discern the main ideas that the grandmothers expressed. For those who talked about self-esteem, we paid particular attention to the links they made between self-esteem and other ideas. In presenting the analyses, we quote at length from the interviews in order to show how the talk unfolded and to make the grandmothers' voices available to the reader.

In keeping with the premise that interviews can be usefully analyzed as communicative events (Briggs, 1986), we also examined how participants used these terms 
over the course of the interview. We paid particular attention to whether they invoked these terms before the researcher asked about them, whether researcher and caregiver were able to create common ground around the topic of self-esteem, and how much grandmothers elaborated on this topic.

\section{Results and Discussion}

\section{American Grandmothers}

All of the American grandmothers were familiar with the term 'self-esteem'. In response to the initial question regarding self-esteem, 'How do you understand the meaning of self-esteem?' all grandmothers were able to provide a definition of selfesteem and responded to at least some of the subsequent questions regarding selfesteem. Like the mothers, they favored the term 'self-esteem' but sometimes used other similar terms, such as 'self-confidence', 'feel good about him/herself', 'inferiority complex', and 'self-image'. Although the grandmothers were not directly asked whether 'self-esteem' and 'self-confidence' had different meanings, examination of their responses revealed that they seemed to use these terms interchangeably. Grandmothers' responses to the self-esteem questions were shorter and less detailed than the mothers' responses, a pattern that did not apply to questions regarding other childrearing matters.

\section{Moderate Self-esteem is Best}

The grandmothers also expressed different beliefs regarding the most desirable level of self-esteem. Unlike their daughters, who believed that there was a difference between high self-esteem and egotism or conceit, only three grandmothers made such a distinction. In other words, when asked, 'Do you think a person's self-esteem could ever be too high?' Centerville mothers said, 'no'. However, most Centerville grandmothers $(11 / 16)$ believed it is indeed possible to have self-esteem that is too high. They described such people as arrogant, self-centered, selfish, and spoiled. Grandmother Anderson (all names are pseudonyms) asserted, 'I also think that there is such a thing as too high of self-esteem maybe as you get older. I mean some people think that they themselves can do no wrong. I think it is harder for them to realize that they are a sinner.' Grandmother James agreed: 'Yeah, well I think sometimes people think maybe they are better than other people, maybe they should always have their way.'

The grandmothers felt that having some self-esteem is desirable, but within limits. Grandmother Kaufman explained that when a person's self-esteem is too high, 'then they're cocky and obnoxious, bossy. But you have to have self-esteem to be successful. It's like everything else. There's a level there . . . it's like these cookies. Three or four are fine. From then on it's bad news. That's the way self-esteem is.' Grandmother Goldman agreed: 'You know you have to feel good about yourself, but you have got to know where the limit is . . you can't let that, "I'm the best", you know go overhead.' Grandmother Stevenson used an example to highlight the importance of promoting well-balanced self-esteem:

[I] tried to balance it out with not making them think they were too hot stuff. Because there's a delicate balance there ... when it gets to the point where [children] think more of themselves than they should or think they are better than other people, when they start thinking that other people aren't as much worth as they are, then there's a danger point. ... We had neighbors who had grandchildren and the parents and the grandchildren 
make the kids almost the ones that ruled the family, which this makes for high self-esteem but it also made for spoiled brats. We discovered that, you know whatever the kid wants, the kid gets kind of thing ... in one way you could say he probably had high self-esteem. In another way you could say he had the wrong role in the family. ... So you can overdo [self-esteem].

According to Grandmother Stevenson, it is the parents' responsibility to monitor their children's self-esteem and know when to pull in the reins so that they do not reach the 'danger point'.

Also implied in this quote from Grandmother Stevenson is the idea that there are other important values that families should be inculcating and these can be overshadowed by self-esteem. This perspective was echoed by Grandmother Perry who asserted that parents' preoccupation with self-esteem was misplaced. She believed that instead of worrying about their children's self-esteem, parents:

Should be worried about their relationship with their children. What they should be worried about uh, their kids growing up as decent human beings ... [realize] they're part of the family, they're part of the community, they're part of the whole network.

\section{Variation Among Grandmothers}

Despite these similarities in the grandmothers' responses, there was also notable variation among the grandmothers, such that two subgroups could be identified. Compared with the mothers, who exhibited strong consensus in their beliefs regarding childrearing and self-esteem, the grandmothers showed greater variation.

Grandmothers Who Echoed Their Daughters. Half of the grandmothers (9/16) responded comfortably to the self-esteem questions, and expressed beliefs that were similar to their daughters. When asked, 'Do you think self-esteem plays an important role in young children's development?' they responded enthusiastically and unequivocally that self-esteem is beneficial to children's development. They believed that selfesteem leads to a variety of psychological strengths, such as happiness, willingness to try new things, persistence, and ability to make friends and interact well with others. These grandmothers also indicated that self-esteem is implicated in many childrearing tasks-discipline (shaming damages self-esteem), praise (sincere praise allows children to feel loved), managing relations between siblings (invidious comparisons damage self-esteem), and achievement (self-esteem is an antecedent and consequence of success).

Several of these grandmothers also spontaneously introduced the notion of selfesteem before the self-esteem questions were asked. Nine grandmothers invoked the term when discussing a range of other childrearing topics, including their socialization goals, praise, and discipline. For example, when Grandmother Brown was asked what type of person she hoped her grandchild would grow up to be, she answered, 'I would say that self-confidence and happiness within yourself is more important than any particular skill or talent you might develop.' Later in the interview, she talked about how she tried to praise and encourage her grandchildren because 'it gives them self-esteem ... they may not be the superstar, but, you know, make them feel good about themselves.' Other grandmothers invoked the notion of self-esteem when discussing their disciplinary methods. For example, Grandmother McLeod felt it was important to make a distinction between the child and the child's misbehavior because 'that self-esteem issue, that issue of liking oneself is critical.' Another grandmother, 
Mrs. Nussbaum, was careful not to shame children because that would 'make their ego or their personality feel like nothing. Or worse than nothing . . . they'd just get a terrible view of themselves. They'd feel unworthy.'

Although these grandmothers echoed their daughters' beliefs, their responses were less elaborated. Whereas the mothers articulated a complex, detailed web of connections between self-esteem and numerous psychological attributes, the grandmothers made fewer such connections. For example, one grandmother linked self-esteem primarily to children's achievement and motivation to meet challenges whereas another focused primarily on self-esteem's merit in developing positive social relationship and maintaining moral autonomy. In other words, although the types of connections that mothers and grandmothers made were similar, mothers wove together many more ideas.

Grandmothers with a Different Point of View. The remaining grandmothers (7/16) differed both from the other grandmothers and from the mothers. They expressed a point of view that involved elements of discomfort or unfamiliarity with self-esteem, awareness of changing childrearing trends, and overt critique. At times, these grandmothers appeared hesitant or tentative, punctuating their responses with pauses, 'ums', and 'I don't knows'. They were less able to articulate how self-esteem was connected to other childrearing issues or to explain why it was important or how it could benefit children. For example, when asked if self-esteem was important to children's development, Grandmother James responded, 'Yeah, I would think so.' But when asked why self-esteem was important, she seemed flustered and uncertain: 'Gosh, ugh! I don't know ... I don't know what to come up with on some of these things ... I'm not a big expert on self-esteem ... I don't know what to say to all of these.' Later, when asked whether she would like to say more about how self-esteem could benefit her grandchildren, she said, 'Not really ... I'm getting tired of self-esteem . . . I just don't have much to say.'

Similarly, when Grandmother Meyer was asked what role parents played in helping children to develop self-esteem, she said, 'Oh golly, how did you come up with all these questions out of your-is this out of a book?' When asked what she would do to enhance her child's self-esteem if she was concerned, she said, 'Golly, I don't know what to say to you on this.' Still later, when asked whether she felt self-esteem affects behavior, she said again, 'Um well, I don't know,' adding, 'I never really, no I don't think about their self-esteem and their behavior or anything. I just got all angels for grandkids so....'

Five of the grandmothers explicitly pointed out that although self-esteem is a 'popular' term now, it was not used in their generation. For example, when asked whether she tried to foster her own children's self-esteem, Grandmother Hartman responded, 'You know, in those days, it wasn't as prominent . . . and you didn't go out of your way to promote that. You just, you know, praise them when they do well in school.' Grandmother Nussbaum added, 'I'm not sure it was called by those words. Um, I can't even think what word we might have used. Pride in doing well or something like that ... [Nowadays, self-esteem] is sort of the "in" thing, you know.'

Similarly, Grandmother Perry said:

I think that the terminology may have changed. Self-esteem is [laughs] overwhelming sometimes. OK. [laughs] . . . This is not a term that I grew up with AT ALL. It is not uhit uh is a term that's used a lot now for kids, well you know better than I do, but I just know that uh who are having problems of one sort or another, easy facile explanation is that they don't have great self-esteem. Yeah, I have my own prejudices [laughs]. 
Grandmother Perry voiced her concerns that low self-esteem is being used as a blanket explanation for any problematic behavior a child exhibits. Other grandmothers also questioned whether the current generation of parents and educators are going 'overboard' with self-esteem and wondered whether this overemphasis on self-esteem could backfire or be maladaptive for children in the long run. For example, Grandmother James said:

Mrs. James: It is kind of a neat trend, this self-esteem trend. They seem to do a lot of that in the some of the schools now, they are trying to make everybody feel good about themselves.

Researcher: Well, that's good, that's ...

Mrs. James: It's good up until a point, but um sometimes you wonder if it's really going to be helpful for them in their whole life. To be praised for so much, for every little bitty thing because when you get out of school, that's NOT going to happen.

Researcher: Right.

Mrs. James: And you'll have to really perform and do something to get all of that praise.

I don't know.

Researcher: Yeah, it's not, it's not the real world.

Mrs. James: I think you can overdo some of that stuff.

Here Grandmother James, who had said earlier that she was 'tired of self-esteem', expressed reservations about the 'self-esteem trend', that 'trying to make everybody feel good' may not be helpful in the 'real world' or the long term. In addition, Grandmother James talked explicitly about self-esteem as highly interconnected with praise.

The reservations that these grandmothers held regarding self-esteem appear to be inextricably tied to their concerns about the current generation's tendency to allocate indiscriminant amounts of praise to children. Grandmother Angelico elaborated:

I think more so in the generation now ... that maybe you can go a little bit overboard. I mean, some things are a part of life ... things that they have to do, um in their household and I don't think they need to be praised for everything, it's just that's expected of them to, to get up and maybe do what they have to do ... for other things they did well, then praise would be a good thing.

Grandmother Wolf, who was 'not crazy about the term self-esteem', explained, 'Well, I don't set out deliberately to do that [foster grandchild's self-esteem]. I think the whole self-esteem thing has kind of gone overboard, but it's not something I think about with him.' When raising her own children, 'We didn't try to go overboard on it . . we deliberately tried not to go overboard with the praise and the pride you know, 'cos we didn't want to instill a presence of self-pride.' Other grandmothers voiced similar concerns. They worried that too much emphasis on praise and self-esteem could lead children to be self-centered or conceited. Grandmother Hartman said:

I find [grandchild] being told you know 'she is wonderful', 'she is great', and to me, if you overdo it, she is going to become a person that has too much self-esteem and she won't be liked by her peers.

In sum, the American grandmothers believed that self-esteem is important to children's development but placed more emphasis than their daughters did on moderate selfesteem and on childrearing practices that balanced self-esteem against other values. In further contrast to the mothers, the grandmothers had less elaborate understandings of self-esteem and differed more among themselves, with half expressing reservations about self-esteem. 


\section{Taiwanese Grandmothers}

The Taiwanese grandmothers were more likely than Taiwanese mothers to find questions regarding self-respect-heart/mind to be puzzling and/or to have little, if anything, to say regarding it. Although all but one of the mothers were familiar with terms related to self-respect-heart/mind, nearly half (7/16) of the grandmothers expressed no familiarity, nor could they say anything about the topic. Among the nine who talked about self-respect-heart/mind, only one grandmother raised the topic before questions were asked. Only three could have defined the term without help from the researcher, and four said that self-respect-heart/mind is not yet visible in their young grandchild but develops later, when the child starts preschool at age 4 or 5 . All but one said that self-respect-heart/mind is not very important to childrearing. Nonetheless, the grandmothers who did speak about self-respect-heart/mind expressed beliefs that were consistent with one another and with the mothers' beliefs. Although a few of the Taiwanese grandmothers used the term self-confidence-heart/mind as well as self-respectheart/mind, the data are insufficient to draw any conclusion regarding whether they used these terms differently.

\section{Self-respect-Heart/Mind: Protect and Moderate It}

The nine grandmothers who talked about self-respect-heart/mind said that a child's self-respect-heart/mind might be hurt if a parent disciplines too severely or without reason. However, most of their comments were very brief. For example, Grandma Ng said, 'If a child doesn't do anything wrong, don't keep yelling at him, otherwise this will hurt his self-respect-heart.' Similarly, Grandma Chiu said that hitting children in public hurts their self-respect-heart/mind and may lead them to do bad things in the future. Grandma Chng, like the others, said that speaking harshly can hurt a child's self-respect-heart/mind; but she also said that praising a child can help her selfconfidence-heart/mind. Grandma Loa said that if a child makes a mistake, it makes her self-respect-heart/mind 'uncomfortable', but did not elaborate further.

Only one participant, Grandma Ang, spoke at any length about how a child's selfrespect-heart/mind can be harmed by an adult's ill-advised actions. She explained that if a child does something wrong, his caregiver should not hit him, but instead should talk to him and explain what he did wrong. If the adult immediately lashes out and hits the child, this will hurt his self-respect-heart/mind, and 'hatred will develop in him'. The child will think to himself, 'I didn't do it wrong twice, it was only one time, and you severely hit and beat me for it!' Hitting the child is advisable only if the child repeats the wrong behavior, after the adult has explained - two or three times - the correct behavior; then hit the child just one time 'so that he'll be afraid'.

Similar to the American grandmothers who held reservations about 'too much' self-esteem, a majority of the Taiwanese grandmothers who discussed selfrespect-heart/mind (7/9) believed that moderate self-respect-heart/mind is best. Four grandmothers said that high or 'strong' (kiong in Tai-gi) self-respect-heart/mind is bad and three said that low or 'weak' (jiok) self-respect-heart/mind is bad. Most of the Taiwanese grandmothers' comments, again, were brief. Three of the grandmothers linked the related term of self-confidence-heart/mind to motivation in both positive and negative ways. When Grandma Kho was asked if a child's self-confidence-heart/ mind could be too strong, she replied, 'You shouldn't have too much self-confidenceheart/mind, just enough is good. If you have too much, then like when taking tests, 


\section{Grace E. Cho et al.}

[a child] will think "I don't have to study" because she is full of self-confidenceheart/mind.' Likewise, Grandma Ong saw too much self-confidence-heart/mind as problematic. She said, 'If [you have] too much self-confidence-heart/mind, when doing things you're less, less daring to do things, more afraid of doing things.' On the other hand, Grandma Chng said that if a person lacks self-confidence-heart/mind, then he lacks courage and is afraid to do things.

The longest and most developed discussion of problems associated with strong or weak self-respect-heart/mind came from Grandma Iu. In contrast to the grandmothers who implicated motivation in their responses, this grandmother said that her eldest son became a 'bad person' due to 'strong' self-respect-heart/mind. She explained that he was a well-behaved child, but now he often quarrels, and neither he nor his wife respectfully addresses herself and her husband despite the fact that she took care of her son's children for 13 years! She explained that this is because his selfrespect-heart/mind is very strong. Then when asked if her young grandchildren have strong self-respect-heart/mind, Grandma Iu said, 'No. How can they? My three grandchildren are good to grandpa and grandma.'

In sum, we found that self-respect-heart was even more peripheral to the Taiwanese grandmothers' folk theories of childrearing than to the Taiwanese mothers'. The minority of grandmothers who talked about self-respect-heart/mind believed that a child's self-respect-heart/mind can be hurt via harsh disciplinary practices and that moderate self-respect-heart/mind is better than either 'strong' or 'weak' self-respectheart/mind. The sense that moderate is best emerged in a related topic, how to handle praise, which played a larger role than self-respect-heart/mind in Taiwanese grandmothers' folk theories of childrearing.

\section{Use Praise Sparingly}

Unlike self-respect-heart/mind, praise was familiar to all the grandmothers we interviewed in Chhan-chng. When asked if they ever praise their child or grandchild, all said that they did. They praised children for 'being good' and used praise to encourage children. For example, Grandma Ong said:

Like sometimes when taking medicine, [I] will also praise him to take it, and then when

he takes it [I] will praise him. If you do that he will then do his best to get it down. . .

Otherwise if you force him, he'll cry and cry.

But many grandmothers (7/16) qualified this practice, claiming that praise should be used sparingly. When asked if she should praise a child who is good, Grandma Ong said, 'I'll be happy in my heart. You can't praise him to his face . . . I will also praise him [laughs], but you shouldn't praise him too much.' Grandma Go responded to the same question more forcefully: 'No need [to praise her]. If she's good, that's enough. Why would you praise her when she's good?' Similarly, Grandma Chiu said, 'Even though my grandson is well-behaved, I will not always tell him that, [because] sometimes you have to praise him and sometimes criticize.' Grandma Chng indicated that praise is problematic because it may interfere with the moral authority a caregiver should maintain. 'I'll also praise him. But can't praise him too often.' She feared that if a child is praised too much, when he grows up, 'I'm afraid he'll turn bad'. Later she explained, 'If you praise a child too much, and then you want to turn a little severe, you can't do it even a little bit.' In other words, praise may intrude on the moral stance one must take when disciplining a child: how could a grandmother praise a child and then turn around and harshly administer corrective discipline? 
Although Taiwanese grandmothers' beliefs regarding praise were similar to some of the American grandmothers' in the emphasis on moderation, it is important to stress that Taiwanese grandmothers did not explicitly link their ideas regarding praise to selfrespect-heart/mind.

\section{Understand the Child's Temperament}

Another topic that the Taiwanese grandmothers elaborated on was the importance of understanding the child's temperament or personality. (There is no English term equivalent in meaning to the Mandarin 'gexing' or Tai-gi 'ko-seng'; both 'temperament' and 'personality' roughly approximate these terms. Therefore, we use 'temperament' and 'personality' interchangeably when translating these Mandarin and Tai-gi terms. In so doing, we remind readers that the translation from Mandarin and Tai-gi to English is not exact.) Unlike the issues of praise and self-respect-heart/mind, which were discussed in response to the interviewer's direct questions, the need to discern the child's personality was not asked directly. However, like the Taiwanese mothers, most (11/16) grandmothers spontaneously invoked this idea and discussed the child's personality in relation to various childrearing tasks.

For example, when Grandma Chng was asked if a child will do bad things if her self-respect-heart/mind is hurt by others, she replied, 'This, you need to look at ... the child's personality.' She explained that because an older child's thought processes are different from a younger child's, the effect of hurting a child's self-respect-heart/ mind will change as she develops. Likewise, when asked about her grandson's selfrespect-heart/mind, Grandma Ang said:

Grandson, you've got to look at his temperament. Some kids have a temper that is not so good, some kids aren't as good at expressing themselves, [they] don't want to talk. We who care for children must go and understand their temperament, and can't use the same method to educate each child.

She thus weaved together three key ideas: (1) the child's temperament varies, (2) it is the caregiver's responsibility to discern the child's temperament, and (3) knowing the child's temperament enables caregivers to devise effective socialization methods. All of the grandmothers concurred on these points.

All 16 grandmothers said that their grandchildren had different personalities. For example, Grandma Iu said:

Different. One is like this and another is like that, really different. This oldest girl is hard to care for, but this younger one is easy. This one's emotions are not good. I feel that these three children each have different personalities.

Most (11/16) of the grandmothers also claimed that it is the caregiver's job to observe the child to discern her temperament or personality. For example, when asked by the researcher, 'Do you think that if a child's self-respect-heart/mind has been hurt, this [child] will go and do bad things?' Grandma Ong replied, 'You've got to look at the child's real nature, some kids' personalities are more sensitive, some are more mature and can understand things, [those] which can think more are less likely to do bad things.' The belief that the adult should 'look at' or 'observe' the child's personality emerged most often in response to questions about self-respect-heart/mind, but also came up in response to other questions. For example, some of the grandmothers claimed that understanding the child's temperament is the basis for knowing how to discipline effectively. When Grandma Koa was asked, 'When a child is older, will you 
change the way you discipline him?' she responded, 'The way to discipline, it's his temperament. You've got to see what kind of temperament he has. We cannot change his temperament.'

In sum, like Taiwanese mothers, Taiwanese grandmothers believed that children have individual temperaments that have to be discovered over time and that caregivers need to take these differences into account in raising their children. Although they did not celebrate individuality for its own sake, they believed that caregivers should be informed by knowledge of the children's individual characteristics. Interestingly, this belief echoed a Confucian proverb 'yin cai shi jiao', or 'teach according to the student's talents'. (Confucian education was privately administered and its method was tailored to meet the needs of the individual student.) Further investigation is necessary to identify the link between this Confucian ideology and the pervasive notion raised by these grandmothers.

\section{Conclusions}

What place, if any, does self-esteem occupy in caregivers' folk theories of childrearing? The results of this study contribute to growing evidence that the answer to this question varies within and across cultures. Although self-esteem emerged as a central organizing concept in the folk theories of middle-class European American mothers of 3-year-olds (Miller et al., 2002), grandmothers from the same families had less complex understandings of self-esteem, placed more emphasis on moderation, and spoke in two voices, either echoing their daughters' discourse or invoking a counter discourse. By contrast, mothers and grandmothers from rural Taiwan resembled one another-but differed from their American counterparts - in expressing childrearing beliefs in which self-respect-heart/mind was peripheral to other more important matters.

In conclusion, we highlight several issues and questions raised by our findings, turning first to issues of cross-cultural comparison. Although different folk theories were expressed by the two sets of grandmothers, there were also points of similarity. For example, support for the idea that self-esteem (or self-respect-heart/mind) is healthiest at moderate levels may be found in both groups. However, this component of their beliefs was contextualized quite differently. Thus, it would be a misinterpretation of our findings to conclude that moderate self-esteem had equivalent meanings for the two groups. Or to say this another way: any given term or idea can only be understood within the larger belief system of which it is an integral part.

Also deserving of further comment is the finding that Taiwanese grandmothers, like their daughters-in-law, placed great emphasis on 'watching' children in order to discern their individual personalities. This folk belief is striking because the concern with individuality seems to be at odds with the literature comparing Americans and East Asians. According to this literature, American children are treated as individuals whose unique preferences and characteristics are cultivated, whereas East Asian children are encouraged to fit in with the group (e.g., Heine et al., 1999; Hsu, 1981/1991; Markus \& Kitayama, 1994; Shweder et al., 1998; Triandis, 1995; Triandis, Bontempo, Villarel, Asai \& Lucca, 1988). Perhaps these divergent findings may be attributed to our ethnographic approach in which we customized our procedures according to local familial and communicative norms. This may have allowed participants to express more fully their own understandings. In fact, the Taiwanese participants were not asked about 'watching' but volunteered this idea. In other words, this unexpected, 
indigenous idea would not have emerged if we had stuck to preconceived questions and coding schemes. In any case, our findings raise an important question for future comparative work: How do parents from different cultures, including 'collectivistic' cultures, understand individual differences in children's personalities? Are such differences celebrated as an end in themselves or are they taken into account in the service of promoting other developmental goals, such as moral development?

Future research should also investigate the breadth of these folk beliefs, considering the rapid pace of change in Taiwan. This study was conducted in one rural community; therefore we do not make claims of generalizability to urban areas. However, there are indications that folk beliefs about childrearing, especially a child's early years, are consistent across much of Taiwan. For example, one of the 'growth industries' in cities throughout Taiwan is a 'Zuo Yuezi Zhongxin' or 'First Month Postpartum Health Center'. This is a place where mothers go with their newborn to rest, recover, and eat a culturally prescribed diet in the first month after giving birth. Traditionally, a mother would observe the postpartum month at home under the care of her mother-in-law, which is still the case in rural areas. Urbanization has not eliminated this traditional practice, but has given rise to another way of observing it. Likewise, Sandel (2000) found that parents in both urban and rural areas consistently look to grandmothers as the preferred source of knowledge about childrearing, even when this conflicts with information spread through local schools, magazines, and television. Many urban-dwelling children were cared for by their paternal grandmother until the age of 2 or 3 . Hence, folk beliefs regarding a child's early years have apparently been adapted to fit urban environments, and their influence is resistant to change due to the continued important role grandmothers play in childrearing.

Turning to generational comparisons, another intriguing finding of this study is the variability among the European American grandmothers. Half of these grandmothers challenged current ideas regarding childrearing and self-esteem. Considered in light of the literature on American parents' folk theories of childrearing and self-esteem (Miller \& Harwood, 2002; Miller et al., 2002; Mintz, 1999; Tamis-LeMonda et al., 2002), these grandmothers emerge as rare dissenters from a dominant folk theory that is 'at large' in American society. In our earlier article, we argued that the pervasiveness of self-esteem in both scientific venues and popular culture naturalizes selfesteem, promoting a type of 'invisibleness' (Miller et al., 2002). However, as members of an earlier generation and as experienced parents who are no longer in the thick of childrearing, it may be easier for grandmothers to take the longer view, reminding us that self-esteem was not always a dominant discourse in American culture, and expressing wariness about the implications of this trend for children's development over the long term.

These generational differences may have implications for children's self-views. It has been documented that the average level of self-esteem in American children and adolescents has been increasing over the past few decades (see meta-analysis by Twenge \& Campbell, 2001). Our findings raise the possibility that changing childrearing beliefs - towards greater emphasis on and valorization of self-esteem-may contribute to this rise in self-esteem levels.

This still leaves us with the question of why some grandmothers dissented from the folk theory of self-esteem embraced by their daughters, whereas other grandmothers endorsed it. These two sets of grandmothers did not differ from one another in median age or geographic distance from their daughters and grandchildren. In other words, it 
is not the case that the grandmothers who challenged the current childrearing trend were from an older cohort than those who accepted it. Nor was it the case that the grandmothers who endorsed the 'self-esteem trend' had more contact with their daughters and grandchildren. Thus, another task for future research will be to replicate this variation and identify its sources.

Finally, bringing together both cross-cultural and generational comparisons, our findings point to greater overlap in folk theories between the Taiwanese generations than between the American generations. This pattern may reflect several factors. The fact that the Taiwanese mothers lived in the same household with their mothers-in-law and abided by norms of deference to the older generation may limit changes in childrearing beliefs and practices from one generation to the next. In the American case, even though the relationship between grandmothers and their daughters seemed to be privileged over that between grandmothers and their daughters-in-law, virtually every grandmother said that she was very careful not to offer childrearing advice to her daughter or infringe on her autonomy as a mother. This posture, in combination with the geographic distance between grandmothers and mothers, makes it likely that American grandmothers have less influence on the childrearing beliefs and practices of the younger generation, thus promoting change in childrearing fashions across generations.

\section{References}

Bloom, L. (1978). Commentary. The Quarterly Newsletter of the Institute for Comparative Human Development, 2, 1-4.

Bock, P. K. (1994). Handbook of Psychological Anthropology. Westport, CT: Greenwood Press.

Bracey, J. R., Cho, G. E. \& Miller, P. J. (2003). African American parents' folk theories of self-esteem. Poster session presented at the biennial meeting of the Society for Research on Child Development, Tampa, FL, April.

Briggs, C. L. (1986). Learning How to Ask: A Sociolinguistic Appraisal of the Role of the Interview in Social Science Research. Cambridge: Cambridge University Press.

Bruner, J. (1990). Acts of Meaning. Cambridge, MA: Harvard University Press.

Bruner, J. (1996). The Culture of Education. Cambridge: Cambridge University Press.

Cervantes, C. A. (2002). Explanatory emotion talk in Mexican immigrant and Mexican American families. Hispanic Journal of Behavioral Sciences, 24, 138-163.

Chan, C. G. \& Elder, G. H. (2000). Matrilineal advantage in grandchild-grandparent relations. Gerontologist, 20, 179-190.

Cho, G. E. \& Miller, P. J. (2004). Personal storytelling: Working-class and middle-class mothers in comparative perspective. In M. Farr (Ed.), Ethnolinguistic Chicago: Language and Literacy in the City's Neighborhoods (pp. 79-101). Mahwah, NJ: Lawrence Erlbaum Associates.

Corsaro, W. A. \& Miller, P. J. (Eds.) (1992). Interpretive Approaches to Children's Socialization (New Directions for Child Development, No. 58). San Francisco, CA: Jossey-Bass.

Erickson, F. D. (1986). Qualitative methods in research on teaching. In M. C. Wittrock (Ed.), Handbook of Research on Teaching (3rd edn, pp. 119-160). New York: Macmillan.

Fung, H. (1994). The socialization of shame in young Chinese children. Unpublished doctoral dissertation, University of Chicago, IL.

Gadsden, V. L. (1999). Black families in intergenerational and cultural perspective. In M. Lamb (Ed.), Parenting and Child Development in 'Nontraditional' Families (pp. 221-246). Mahwah, NJ: Lawrence Erlbaum Associates.

Garcia Coll, C. \& Pachter, L. M. (2002). Ethnic and minority parenting. In M. Bornstein (Ed.), Handbook of Parenting: Vol. 4 (2nd edn, pp. 1-20). Mahwah, NJ: Lawrence Erlbaum Associates.

Gaskins, S., Miller, P. J. \& Corsaro, W. A. (1992). Theoretical and methodological perspectives in the interpretive study of children. In W. A. Corsaro \& P. J. Miller (Eds.), Interpretive 
Approaches to Children's Socialization (New Directions for Child Development No. 58) (pp. 5-23). San Francisco, CA: Jossey-Bass.

Goncu, A. (Ed.) (1999). Children's Engagement in the World. New York: Cambridge University Press.

Grant, J. (1998). Raising Baby by the Book: The Education of American Mothers. New Haven, CT: Yale University Press.

Greenfield, P. M. \& Cocking, R. R. (1994). Cross-cultural Roots or Minority Child Development. Hillsdale, NJ: Lawrence Erlbaum Associates.

Greenfield, P. M. \& Suzuki, L. (1998). Culture and human development: Implications for parenting, education, pediatrics, and mental health. In I. E. Sigel \& K. A. Renninger (Eds.), Handbook of Child Psychology: Vol. 4. Child Psychology in Practice (5th edn, pp. 10591109). New York: Wiley.

Harkins, J. \& Wierzbicka, A. (2001). Emotions in Crosslinguistic Perspective. New York: Mouton de Gruyter.

Harkness, S. \& Super, C. M. (1992). Parental ethnotheories in action. In I. Sigel, A. McGillicuddy-DeLisi \& J. Goodnow (Eds.), Parental Belief Systems: The Psychological Consequences for Children (pp. 373-391). Hillsdale, NJ: Lawrence Erlbaum Associates.

Harkness, S. \& Super, C. M. (1996). Parents' Cultural Belief Systems: Their Origins, Expressions, and Consequences. New York: Guilford Press.

Harwood, R. L., Miller, J. G. \& Irizarry, N. L. (1995). Culture and Attachment. New York: Guilford Press.

Harwood, R. L., Schoelmerich, A., Schulze, P. A. \& Gonzalez, Z. (1999). Cultural differences in maternal beliefs and behaviors: A study of middle-class Anglo and Puerto Rican motherinfant pairs in four everyday situations. Child Development, 70, 1005-1016.

Heine, S. J. \& Lehman, D. R. (2003). Move the body, change the self: Acculturative effects on the self-concept. In M. Schaller \& C. Crandall (Eds.), Psychological Foundations of Culture (pp. 305-331). Mahwah, NJ: Lawrence Erlbaum Associates.

Heine, S. J., Lehman, D. R., Markus, H. R. \& Kitayama, S. (1999). Is there a universal need for positive self-regard? Psychological Review, 106, 766-794.

Ho, D. Y. F. (1987). Fatherhood in Chinese culture. In M. E. Lamb (Ed.), The Father's Role: Cross-cultural Perspectives (pp. 227-245). Hillsdale, NJ: Lawrence Erlbaum Associates.

Hsu, F. L. K. (1991). Americans and Chinese: Passages to differences (3rd edn). Taipei, Taiwan: Bookman Books Ltd. (Original work published 1981.)

Hulbert, A. (2003). Raising America: Experts, Parents, and a Century of Advice about Children. New York: Knopf.

Jessor, R., Colby, A. \& Shweder, R. A. (Eds.) (1996). Ethnography and Human Development: Context and Meaning in Social Inquiry. Chicago, IL: University of Chicago Press.

Liu, K. C. Y. \& Chien, C. Y. (1998). Project approach and parent involvement in Taiwan. Childhood Education, 74, 213-219.

Markus, H. R. \& Kitayama, S. (1991). Culture and the self: Implications for cognition, emotion, and motivation. Psychological Review, 98, 224-253.

Markus, H. R. \& Kitayama, S. (1994). Culture, Self, and Emotion. Washington, DC: American Psychological Association.

Miller, A. M. \& Harwood, R. L. (2002). The cultural organization of parenting: Change and stability of behavior patterns during feeding and social play across the first year of life. Parenting: Science and Practice, 2, 241-272.

Miller, J. G. (1994). Cultural psychology: Bridging disciplinary boundaries in understanding the cultural grounding of self. In P. Bock (Ed.), Handbook of Psychological Anthropology (pp. 139-170). Westport, CT: Greenwood Press.

Miller, P. J., Fung, H. \& Mintz, J. (1996). Self-construction through narrative practices: A Chinese and American comparison of early socialization. Ethos, 24, 1-44.

Miller, P. J., Hengst, J. A. \& Wang, S. (2003). Ethnographic methods: Applications from developmental cultural psychology. In P. Camic \& J. Rhodes (Eds.), Qualitative Research in Psychology: Expanding Perspectives in Methodology and Design (pp. 219-242). Washington, DC: American Psychological Association.

Miller, P. J., Wang, S., Sandel, T. \& Cho, G. E. (2002). Self-esteem as folk theory: A comparison of European American and Taiwanese mothers' beliefs. Parenting: Science and Practice, 2, 209-239. 
Miller, P. J., Wiley, A. R., Fung, H. \& Liang, C. (1997). Personal storytelling as a medium of socialization in Chinese and American families. Child Development, 68, 557-568.

Mintz, J. (1999). Self-esteem as ideology and practice: A study of narrative discourse practices among parents and preschool children in a middle-class, European-American community. Unpublished doctoral dissertation, University of Chicago, IL.

Okagaki, L. \& Divecha, D. J. (1993). Development of beliefs. In T. Luster \& L. Okagaki (Eds.), Parenting: An Ecological Perspective (pp. 35-67). Hillsdale, NJ: Lawrence Erlbaum Associates.

Parke, R. D. \& Buriel, R. (1997). Socialization in the family: Ethnic and ecological perspectives. In W. Damon (Ed.), Handbook of Child Psychology: Vol. 3. Social, Emotional and Personality Development (pp. 463-552). New York: Wiley.

Sandel, T. L. (2000). Leading children in Chhan-chng: Language socialization in a Taiwanese community. Unpublished doctoral dissertation, University of Illinois at Urbana-Champaign, IL.

Sandel, T. L. (2002). Kinship address: Socializing young children in Taiwan. Western Journal of Communication, 66, 257-280.

Sandel, T. L. (2003). Linguistic capital in Taiwan: The KMT's Mandarin language policy and its perceived impact on language practices of bilingual Mandarin and Tai-gi speakers. Language in Society, 32, 523-551.

Sandel, T. L. (2004). Narrated relationships: Mothers-in-law and daughters-in-law justifying conflicts in Taiwan's Chhan-chng. Research on Language and Social Interaction, 37, 365-398.

Shweder, R. A., Goodnow, J., Hatano, G., LeVine, R. A. Markus, H. \& Miller, P. J. (1998). The cultural psychology of development: One mind, many mentalities. In W. Damon \& R. M. Lerner (Eds.), Handbook of Child Psychology: Vol. 1 (5th edn, pp. 865-937). New York: Wiley \& Sons.

Smith, P. K. (1995). Grandparenthood. In M. Bornstein (Ed.), Handbook of Parenting: Vol. 3 (1st edn, pp. 89-112). Mahwah, NJ: Lawrence Erlbaum Associates.

Smith, P. K. \& Drew, L. M. (2002). Grandparenthood. In M. Bornstein (Ed.), Handbook of Parenting: Vol. 3 (2nd edn, pp. 141-172). Mahwah, NJ: Lawrence Erlbaum Associates.

Stafford, C. (1995). The Roads of Chinese Childhood: Learning and Identification in Angang. New York: Cambridge University Press.

Stevenson, H. W. \& Stigler, J. W. (1992). The Learning Gap: Why our Schools are Failing and What We Can Learn from Japanese and Chinese Education. New York: Summit Books.

Stevenson, H. W., Lee, S. Y., Chen, C., Stigler, J. W., Hsu, C. C. \& Kitamura, S. (1990). Contexts of achievement: A study of American, Chinese, and Japanese children. Monographs of the Society for Research in Child Development, 55, 1-2.

Strom, R., Strom, S. \& Shen, Y. L. (1996). Grandparents in Taiwan: A three-generational study. International Journal of Aging \& Human Development, 42, 1-19.

Suarez-Orozco, C. \& Suarez-Orozco, M. M. (2001). Children of immigration. Cambridge, MA: Harvard University Press.

Sun, L. C. \& Roopnarine, J. L. (1996). Mother-infant, father-infant interaction and involvement in childcare and household labor among Taiwanese families. Infant Behavior and Development, 19, 121-129.

Tamis-LeMonda, C. S., Wang, S., Koutsouvanou, E. \& Albright, M. (2002). Childrearing values in Greece, Taiwan, and the United States. Parenting: Science and Practice, 2, 185-208.

Triandis, H. C. (1990). Cross-cultural studies of individualism and collectivism. In J. Berman (Ed.), Nebraska Symposium on Motivation, 1989 (pp. 41-133). Lincoln, NB: University of Nebraska Press.

Triandis, H. C. (1995). Individualism-collectivism. Boulder, CO: Westview Press.

Triandis, H. C., Bontempo, R., Villarel, M. J., Asai, M. \& Lucca, N. (1988). Individualism and collectivism: Cross-cultural perspectives on self-ingroup relationships. Journal of Personality and Social Psychology, 54, 323-338.

Twenge, J. M. \& Campbell, W. K. (2001). Age and birth cohort differences in self-esteem: A cross-temporal meta-analysis. Personality and Social Psychology Review, 5, 321-344.

Wierzbicka, A. (1999). Emotions across Languages and Cultures. New York: Cambridge University Press. 
Wiley, A. R., Rose, A. J., Burger, L. K. \& Miller, P. J. (1998). Constructing autonomous selves through narrative practices: A comparative study of working-class and middle-class families. Child Development, 69, 833-847.

Wolf, M. (1978). Child training and the Chinese family. In M. Freedman (Ed.), Family and Kinship in Chinese Society (pp. 37-62). Stanford, CA: Stanford University Press.

Wolf, M. (1987). Women and the Family in Rural Taiwan. Taipei, Taiwan: Caves Books. (Original work published 1972.)

Wolf, M. (1992). A Thrice Told Tale: Feminism, Postmodernism \& Ethnographic Responsibility. Stanford, CA: Stanford University Press.

Woolcott, H. F. (1995). The Art of Fieldwork. Walnut Creek, CA: Altamira Press.

\section{Acknowledgments}

This research was funded by a grant from the Spencer Foundation awarded to Peggy J. Miller. We would like to thank all the families in both the United States and Taiwan who participated in the study. We extend our appreciation to the members of the Hsu family for their assistance in recruiting participants in Taiwan. We also gratefully acknowledge the efforts of Donna Ching-kuei Sandel and our team of undergraduate and graduate research assistants, including Wen-yu Chao, Sophia Chen, Cassandra Fujitani, Julie Gibbons, Wen-ting Lin, and Mary O'Kelly.

\section{Note}

1. When comparing the interview/conversation situation across the two sites, it is important to point out that the Centerville mothers and grandmothers were all interviewed separately, whereas roughly half of the Chhan-chng participants conversed with the researcher in the presence of the other party. Although we tried to schedule separate, one-on-one interviews in Chhan-chng, this was not feasible in seven cases. This raises the possibility that these Taiwanese participants may have felt constrained when expressing their beliefs in the presence of the other party. In a separate analysis of these same families, Sandel (2004) examined reported narratives of conflict between mothers- and daughters-in-law. He found that collective folk values of deference to elders played a major role in how conflicts were reported, narrated, and interpreted. That is, a mother-in-law may criticize a daughter-in-law or express a contrary opinion without fear of communal censure but the reverse pattern is disallowed. In other words, there is a normative asymmetry: mothers-in-law are free to air their opinions and voice criticisms but their daughters-in-law are not. This implies that the Taiwanese grandmothers were free to express their childrearing beliefs in conversations with the researcher whether or not their daughters-in-laws were present, just as their American counterparts (who were interviewed alone) were free to express their views.

It also implies that the Taiwanese mothers would hesitate to express divergent views in the presence of their mothers-in-law. However, the mothers had access to a linguistic resource - strategic codeswitching - that their mothers-in-law did not. According to Sandel (2003), due to the impact of Taiwan's changing language situation, most grandmothers in this community were monolingual (Tai-gi [Taiwanese]) speakers whereas all mothers were bilingual (Tai-gi and Mandarin). Furthermore, these two Chinese languages are mutually unintelligible. Some mothers code-switched from Tai-gi (the language spoken most often in the home) to Mandarin when they did not want their mothers-in-law to understand what they were saying. In sum, in light of these complex cultural and linguistic factors, it is impossible to say exactly how the conversations between Taiwanese mothers and researchers were affected by the presence of the mother-in-law. However, it is likely that the experience of living with and deferring to the mother-in-law had a more constraining effect on Taiwanese mothers' childrearing beliefs, compared with their European American counterparts. 